\title{
Modelling and Optimizing the Removal of Methylene Blue by a Mixture of Titaniferous Sand and Attapulgite Using Complete Factorial Design
}

\author{
Kalidou Ba, \\ Alpha Ousmane Toure, \\ El Hadji Moussa Diop, \\ Falilou Mbacke Sambe, \\ Codou Guéye Mar Diop, \\ Laboratory Water-Energy-Environnment-Industrials Processes \\ Ecole Supérieure Polytechnique (ESP), Cheikh Anta DIOP University of \\ Dakar-Fann, Senegal
}

Doi:10.19044/esj.2021.v17n40p1

Submitted: 02 August 2021

Accepted: 27 October 2021

Published: 30 November 2021
Copyright 2021 Author(s)

Under Creative Commons BY-NC-ND

4.0 OPEN ACCESS

Cite As:

Ba K., Toure A.O., Diop E. H.M., Sambe M.F., \& Diop C.G.M., (2021). Modelling and Optimizing the Removal of Methylene Blue by a Mixture of Titaniferous Sand and Attapulgite Using Complete Factorial Design. European Scientific Journal, ESJ, 17(40), 1.

https://doi.org/10.19044/esj.2021.v17n40p1

\section{Abstract}

This paper focuses on the removal of methylene blue by adsorption using a mixture of titaniferous sand and attapulgite. The different adsorbents were characterized by X-ray fluorescence spectroscopy and their different parameters such as $\mathrm{pH}$, zero charge potential, and specific surface area were determined. The experiments performed were optimized and modeled by a full 2-level and 4-factor design. The four factors are the ratio of titaniferous sand and attapulgite, the concentration of methylene blue, $\mathrm{pH}$, and time. These vary from 4 to 19, 20 to $100 \mathrm{mg} / \mathrm{L}, 2$ to 9 , and 30 to 150 min respectively. The study of the effects of the different factors showed that the effect of methylene blue concentration and $\mathrm{pH}$ significantly influence the adsorption capacity and removal efficiency of the dye. The optimum parameters (adsorbent ratio, adsorbate concentration, $\mathrm{pH}$ and time) obtained for the adsorption capacity through the desirability function are: $19,100 \mathrm{mg} / \mathrm{L}, 9$ and $150 \mathrm{~min}$. Those obtained for the yield are: 4, 100mg/L, 9, 150min. The pseudo second order adsorption kinetics gave an equilibrium adsorption capacity qe $($ calculated $)=$ 
$7.6863 \mathrm{mg} / \mathrm{g}$ which is almost equal to that obtained experimentally qe $(\exp )=$ $7.3562 \mathrm{mg} / \mathrm{g}$. This shows that the pseudo second order kinetic model is the adequate mathematical model to describe the methylene blue adsorption phenomenon on the mixture of titaniferous sand and attapulgite. The thermodynamic study showed that the methylene blue adsorption reaction is exothermic, non-spontaneous, and the degree of disorder of the particles at the adsorbing surface decreases.

Keywords: Factorial design, Adsorption, Methylene blue, Titanium sand, Attapulgite

\section{Introduction}

Effluents from textile industries contain highly toxic and nonbiodegradable coloured organic molecules, which are released into the receiving environment, causing huge problems for the environment and human health (Oladipo et al., 2014; Venkataraghavan et al., 2020). Methylene blue is the most widely used dye in silk and cotton dyeing. Its inhalation and ingestion can cause breathing difficulties and burning sensation respectively (Karim et al., 2010; Taylor et al., 2015). Therefore, it is important to implement treatment methods to remove these dyes. Several remediation techniques have been implemented which includes physical, chemical, biological, conventional oxidation, and membrane processes (Aarfane et al., 2014; El-Sayed, 2011; Gürses et al., 2006). The major challenge of these different methods results on one hand from the difficulty to completely remove some recalcitrant molecules and on the other hand from the high cost of implementing these techniques (Abbaz et al., 2014). In recent years, adsorption on activated carbon seems to be the most studied and used process due to its efficiency and ease of implementation. This is why its disadvantages are mainly related to the problem of energy cost for its calcination and the problem of regeneration (Biophys et al., 2014; Ozer et al., 2012; Salem \& Elmaazawi, 2000). These major constraints have led to the reorientation of the application of this method with other adsorbents of natural origin, which are easier to handle and less expensive (Benguella \& Yacouta-Nour, 2009; Bonetto et al., 2015; Gupt et al., 2020).

In this work, we report the use of full factorial design to carry out the experimental series, to develop more accurate models, and to optimize the different process variables. The adsorption process was optimized by varying four variables, namely the ratio of the two adsorbents, the $\mathrm{pH}$ of the solution, the initial concentration of $\mathrm{MB}$, and the contact time. In addition, the study of kinetics and thermodynamics were also carried out to reveal the adsorption mechanism. 


\section{Material and Methods \\ Material}

\section{Adsorbate}

The target pollutant in this study is methylene blue (MB), which is also known as tetramethylthionine hydrochloride. Methylene blue (Figure 1) is a cationic dye with a molecular weight of $319.85 \mathrm{~g} / \mathrm{mol}$ that belongs to the group of quinone imides in the Thiazine section. They are sulphur dyes in which two benzene rings are joined by a closed ring consisting of one nitrogen atom, one sulphur atom, and four carbon atoms.

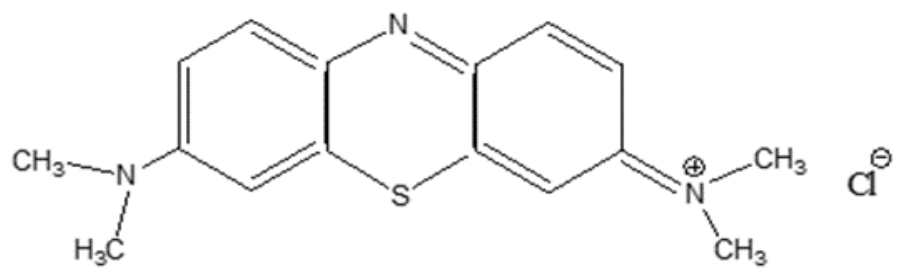

Figure 1. Structure of Methylene Blue

\section{Adsorbents}

The adsorbents used in this work are titaniferous sand and attapulgite. The titaniferous sand is a residue of a mining industry located in Senegal. Its treatment was carried out by putting it in contact with a sulphuric acid solution of concentration $4 \mathrm{M}$. The mixture was stirred for 4 hours to ensure maximum contact with the acid. At the end of the operation, the sand is recovered and washed several times with distilled water until a $\mathrm{pH}$ close to neutrality is obtained. It is then dried in an oven for 24 hours and placed in tinted glass bottles for later use. The other material, namely attapulgite, has not undergone any prior treatment and is used in a raw manner in the work.

\section{Methods}

\section{Determination of Isoelectric Point}

The pHpzc was determined by introducing into 250mL Erlenmeyer flasks a $2 \mathrm{~g}$ of adsorbent, and $50 \mathrm{~mL}$ of a sodium chloride solution (0.1M). These solutions were adjusted to $\mathrm{pH}$ values between 2 and 12 using $\mathrm{NaOH}$ and $\mathrm{HCl}(0.1 \mathrm{M})$ solutions. The suspensions were kept under constant agitation for 24 hours at room temperature. The $\mathrm{pH}$ values corresponding to the final step are recorded. The meeting point of the two curves $\mathrm{pH}_{\text {final }}=\mathrm{f}\left(\mathrm{pH}_{\text {initial }}\right)$ and $\mathrm{pH}_{\text {final }}=\mathrm{pH}_{\text {initial }}$ gives the isoelectric point (El-Sayed, 2011). 


\section{Determination of the Nature of the Adsorbent}

The acidic or basic nature of the adsorbent was determined by mixing $1 \mathrm{~g}$ of the adsorbent with $100 \mathrm{~mL}$ of distilled water. The mixture was stirred for 1hour at room temperature and the suspension was filtered to measure the $\mathrm{pH}$ of the final solution. This value gives an idea about the acidic or basic character of the adsorbent (Das, 2014).

\section{Determination of the Specific Surface}

The specific surface area of the adsorbents was estimated using the Sear's method. This consists of introducing $0.5 \mathrm{~g}$ of adsorbent into a previously prepared salt solution (10g of $\mathrm{NaCl}$ in $50 \mathrm{~mL}$ of distilled water) and adjusting the $\mathrm{pH}$ to a value of 3 using $0.1 \mathrm{~N}$ chloridric acid. The reaction mixture is then measured with $0.1 \mathrm{~N} \mathrm{NaOH}$. The volume $(\mathrm{V})$ of $\mathrm{NaOH}$ is to be poured in to raise the $\mathrm{pH}$ from 3 to 9 so as to allow the value of the specific surface of the adsorbents to be estimated (Bhattacharyya \& Gupta, 2007). It is deduced from the following relationship:

$$
\mathrm{S}\left(\mathrm{m}^{2} / \mathrm{g}\right)=32 \mathrm{~V}-25
$$

\section{Adsorption in Batch Mode}

Batch adsorption experiments were performed in glass reactors containing $50 \mathrm{~mL}$ of $\mathrm{MB}$ solution of given concentration to which an appropriate ratio of adsorbents was added. The reactors were stirred at a constant speed of $750 \mathrm{rpm}$ in a multi-stage stirrer. The operating parameters such as ratio, initial $\mathrm{MB}$ concentration, $\mathrm{pH}$, and contact time were studied and optimized for maximum $\mathrm{MB}$ removal based on the screening design methodology. After the experiment was completed, the residual MB concentration was measured using a UV-Vis spectrophotometer (Agilent technologies Cary 60) at a wavelength of $653 \mathrm{~nm}$ which corresponds to the maximum absorbance of the MB dye. The adsorption capacity (mg.g-1) and removal efficiency (\%) were determined using equations 2 and 3 respectively:

$$
\begin{aligned}
& q_{e}=\frac{\left(C_{i}-C_{f}\right) * V}{m} \\
& r=\left(\frac{C_{f}-C_{f}}{C_{i}}\right) * 100
\end{aligned}
$$

Where:

$\mathrm{C}_{\mathrm{i}}$ : The initial concentration $(\mathrm{mg} / \mathrm{L})$;

$\mathrm{C}_{\mathrm{f}}$ : The final concentration $(\mathrm{mg} / \mathrm{L})$;

$\mathrm{m}$ : The total mass of the two adsorbents (g); 


\section{Full Factorial Design Modeling}

The study of the effects of different adsorption parameters by conventional methods remains tedious and time consuming. However, in order to better understand the effects of different factors such as ratio, initial dye concentration, $\mathrm{pH}$ and time, as well as their interactions, a $2^{\mathrm{k}}$ factorial design was carried out. These two levels are called high and low and have the values +1 and -1 respectively. The letter $\mathrm{k}$ represents the number of factors. The design of this factorial plan allows on one hand the reduction of the number of experiments to be carried out and on the other hand to avoid carrying out a series of independent studies. The significance of the independent variables and their interactions were tested by analysis of variance (ANOVA). To express the observed response as a function of the experimental factors, the second-order polynomial model was selected and is written as follows:

$Y=\beta_{0}+\sum_{i=1}^{k} \beta_{i} X_{i}+\sum_{i 3=1}^{k} \beta_{i i} X_{i i}^{2}+\sum_{i=1}^{k} \sum_{i=j=1} \beta_{i j} X_{i} X_{(4)}$

Where $\beta_{0}$ is the constant, $\beta_{\mathrm{i}}$ and $\beta_{\mathrm{ii}}$ are the linear and quadratic coefficients of the input variable $X_{i}$ respectively, and $\beta_{i j}$ is the interaction coefficient of the input variables $X_{i}$ and $\mathrm{X}_{\mathrm{j}}$. Furthermore, the experimental design, the regression coefficients of the models, the analysis of variances, and the graphs were determined using the software called Statgraphics Centurion XV (version 16.2).

\section{Results and Discussion}

\section{Adsorbents and Adsorbate Parameters}

The values of the various parameters of the adsorbents and adsorbate as well as the results of the X-ray fluorescence characterization are recorded in Tables 1 and 2 respectively.

Table 1. The Different Parameters of the Adsorbents and the Adsorbate

\begin{tabular}{cccc} 
Adsorbents/Adsorbate & $\begin{array}{c}\text { Titaniferous } \\
\text { Sand }\end{array}$ & Attapulgite & Methylene Blue \\
\hline $\mathrm{pH}$ & 6.4 & 8.21 & 6.21 \\
\hline $\mathrm{pHpzc}$ & 8.75 & 8.75 & - \\
\hline Specific surface area $\left(\mathrm{m}^{2} / \mathrm{g}\right)$ & 13.4 & 70.68 & -
\end{tabular}

\begin{tabular}{ccccccc} 
Sample & Units & Ni & Al & Fe & Mn & Ca \\
\hline $\begin{array}{c}\text { Titaniferous sand }+\mathrm{H}_{2} \mathrm{SO}_{4} \\
(4 \mathrm{M})\end{array}$ & $\mathrm{ppm}$ & 92.77 & 18676.65 & 229129.56 & 6573.29 & 2233.36 \\
\hline Raw titaniferous sand & $\mathrm{ppm}$ & 66.4 & 22695.45 & 272074.78 & 8107.22 & 2450.83 \\
\hline Attapulgite & $\mathrm{ppm}$ & $<$ LOD & 24737.43 & 17829.26 & 388.91 & 11952.21
\end{tabular}


Table 2. X-ray Fluorescence Analysis of Samples

\begin{tabular}{cccccccccc}
$\mathbf{S i}$ & $\mathbf{Z n}$ & $\mathbf{V}$ & $\mathbf{C d}$ & $\mathbf{K}$ & $\mathbf{Z r}$ & $\mathbf{T i}$ & $\mathbf{P}$ & $\mathbf{C r}$ & As \\
\hline 63423.27 & 182 & 750.3 & $<\mathrm{LOD}$ & $<\mathrm{LOD}$ & 2421.75 & $3 \mathrm{E}+05$ & 1130.31 & 1116.39 & 149.35 \\
\hline 82240.62 & 211 & 852.2 & $<$ LOD & $<$ LOD & 2407.55 & $3 \mathrm{E}+05$ & 1631.17 & 1142 & 187.54 \\
\hline 408028.69 & 101 & 89.82 & 4.55 & 1105 & 53.61 & 1303 & 2159.72 & 514.58 & 7.3
\end{tabular}

\begin{tabular}{ccccccc} 
Se & S & Cl & Ba & Sn & Ag & Mo \\
\hline 15.94 & 544.35 & 167.69 & $<$ LOD & 28.71 & $<$ LOD & $<$ LOD \\
\hline 19.29 & 457.9 & 168.52 & 193.57 & 51.59 & 50.68 & 14.21 \\
\hline$<$ LOD & $<$ LOD & 189 & $<$ LOD & $<$ LOD & $<$ LOD & 12.55
\end{tabular}

\begin{tabular}{cccccc}
$\mathbf{N b}$ & $\mathbf{S r}$ & $\mathbf{R b}$ & $\mathbf{B i}$ & $\mathbf{A u}$ & $\mathbf{C o}$ \\
\hline 430.57 & 6.04 & $<$ LOD & $<$ LOD & 105.8 & $<$ LOD \\
\hline 570.32 & 14.04 & $<$ LOD & 44.58 & 139.88 & 414.64 \\
\hline 16.89 & 71.02 & 14.27 & 1.63 & $<$ LOD & $<$ LOD
\end{tabular}

The elemental analysis of the raw and activated titaniferous sand (Table 2) shows that titanium, iron, and aluminium are the predominant elements present at concentrations of 300,000 ppm, 63423.27 ppm and 18676.65 ppm respectively, followed by silicon. This confirms the presence of oxides such as titanium dioxide, iron oxide, and alumina which are essential elements in the adsorption of refractory organic compounds. Elements such as manganese, calcium, zircon, phosphorus, and chromium are present in a minority. Furthermore, silicon is the predominant element in the case of nonactivated attapulgite, followed by aluminium, iron, and calcium. It also shows the presence of silica, alumina, and iron oxide respectively. In addition, activation of the titaniferous sand with a sulphuric acid solution resulted in a considerable reduction in the content of iron, aluminium, silicon, and manganese.

\section{pH Zero Charge Point: pHpzc}

The $\mathrm{pH}$ zero charge point is the $\mathrm{pH}$ value at which the net charge on the surface of the adsorbent is zero. The $\mathrm{pH}_{\mathrm{pzc}}$ value for titaniferous sand and attapulgite found from Figure 2 is 8.75 . For $\mathrm{pH}$ values above $\mathrm{pH}_{\mathrm{pzc}}$, the surface of the adsorbent will be negatively charged by deprotonation of the functional groups on the surface of the adsorbent. Under these conditions, the support is ready to attract any cationic compound resulting in an increase in the electrostatic force between the negative charge of the adsorbent and the positive charge of the dye. For $\mathrm{pH}$ values below pHpzc, the surface of the support is positively charged and adsorption with anionic dyes is much more favoured. Similar results have been reported on the study of methylene blue 
adsorption on eucalyptus and palm biomaterial which depends on the particle size (Abdallah et al., 2016; El-Sayed, 2011).
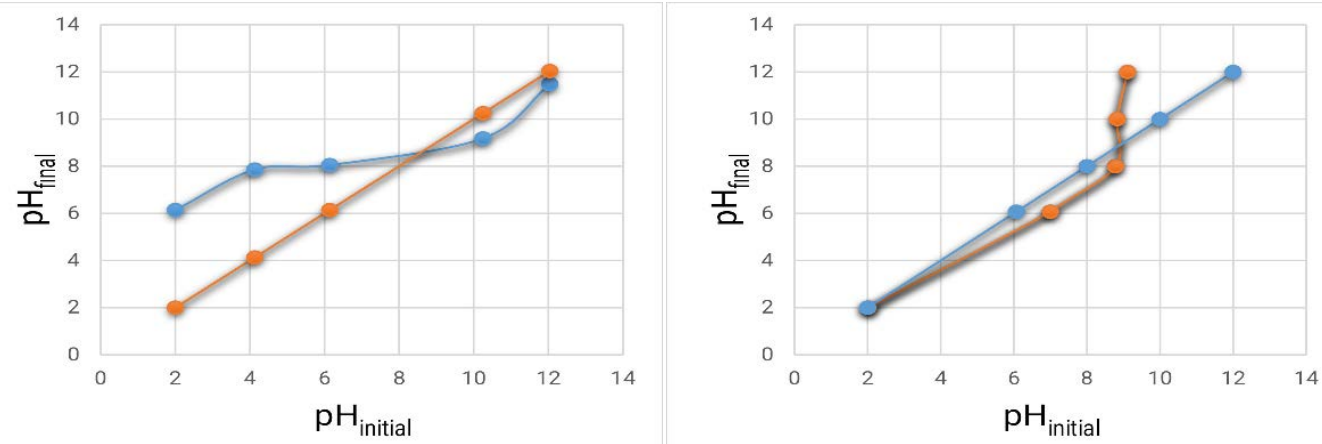

Figure 1. Isoelectric Point of Attapulgite (a) and Titaniferous Sand (b)

\section{Contact Time}

In order to study the effect of contact time on the efficiency of the adsorption process, batch adsorption experiments were carried out with a fixed adsorbent ratio of 5 (a $0.5 \mathrm{~g}$ mass of titaniferous sand combined with a $0.1 \mathrm{~g}$ mass of attapulgite) and at an initial MB concentration of $100 \mathrm{mg} \cdot \mathrm{L}^{-1}$ while varying the contact time from 30 to $240 \mathrm{~min}$. Samples were taken at predetermined time intervals to analyze the residual MB concentration in the solution. The amount of methylene blue adsorbed by attapulgite increases very rapidly with time up to $60 \mathrm{~min}$, and then decreases slowly to reach equilibrium with effective adsorption after an optimum time of $150 \mathrm{~min}$. A slight increase in the adsorbed amount of methylene blue is noted up to 140 min with the composite material, and the corresponding equilibrium time is $150 \mathrm{~min}$. Furthermore, the amount adsorbed by the titaniferous sand evolves weekly to reach the equilibrium from 150 min (Figure 3).

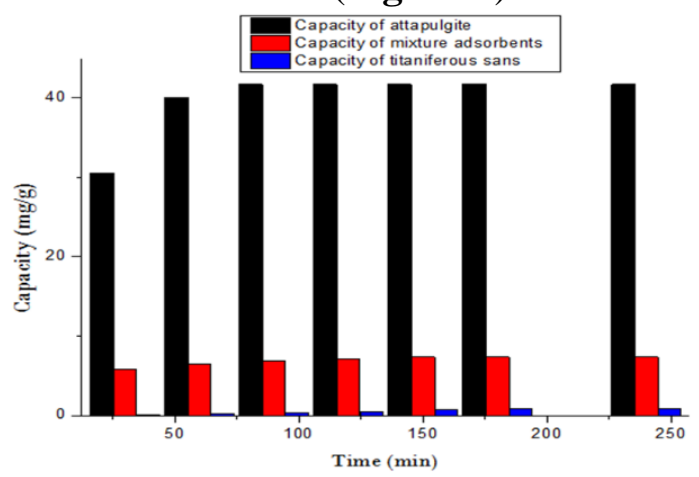

Figure 2. Evolution of the Adsorption Capacity of Attapulgite, the Mixture of the Two Adsorbents and Titaniferous Sand as a Function of Time $\left(\mathbf{p H}=\mathbf{6 . 2 1}, \mathbf{C}_{\mathbf{M B}}=\mathbf{1 0 0} \mathbf{~ m g} / \mathbf{L}, \mathbf{V = 5 0}\right.$ $\mathrm{mL}, \mathrm{T}=25^{\circ} \mathrm{C}, \mathrm{m}_{\text {attapulgite }}=0.1 \mathrm{~g}$ and $\left.\mathrm{m}_{\text {sable }}=0.5 \mathrm{~g}\right)$. 


\section{Description of the Experimental Plan}

For the design of the adsorption process, a complete two-level and four-factor design $\left(2^{4}\right)$ was performed. The high and low levels of the different variables in this study including ratio, concentration, $\mathrm{pH}$ and time are 4 and 19, 20 and $100 \mathrm{mg} / \mathrm{L}, 2$ and 9, and 30 and $150 \mathrm{~min}$ respectively. The levels of the parameters studied and the different tests carried out are summarized in Tables 3 and 4 respectively:

\begin{tabular}{cccccccc} 
Essay & bloc & Ratio & Concentration & $p H$ & Time & Capacity & Yield \\
& & & & & & & mg/g \\
\hline & & & $\mathbf{m g} / \mathbf{L}$ & & $\mathbf{~ m n}$ & 0.11 & 43.75 \\
\hline 1 & 1 & 4.00 & 20.00 & 2.00 & 30.00 & 1.19 & 95.34 \\
\hline 2 & 1 & 19.00 & 100.00 & 9.00 & 30.00 & 0.07 & 28.41 \\
\hline 3 & 1 & 19.00 & 20.00 & 2.00 & 150.00 & 1.12 & 90.00 \\
\hline 5 & 1 & 4.00 & 100.00 & 9.00 & 150.00 & 0.38 & 52.50 \\
\hline 6 & 2 & 4.00 & 100.00 & 2.00 & 30.00 & 0.13 & 78.73 \\
\hline 7 & 2 & 19.00 & 20.00 & 9.00 & 30.00 & 39.64 \\
\hline 8 & 2 & 19.00 & 100.00 & 2.00 & 150.00 & 0.85 & 75.79 \\
\hline 9 & 3 & 19.00 & 100.00 & 2.00 & 30.00 & 0.49 & 29.25 \\
\hline 10 & 3 & 4.00 & 20.00 & 9.00 & 30.00 & 0.19 & 37.95 \\
\hline 11 & 3 & 4.00 & 100.00 & 2.00 & 150.00 & 0.36 & 76.70 \\
\hline 12 & 3 & 19.00 & 20.00 & 9.00 & 150.00 & 0.09 & 82.50 \\
\hline 13 & 4 & 19.00 & 20.00 & 2.00 & 30.00 & 0.19 & 32.73 \\
\hline 14 & 4 & 4.00 & 100.00 & 9.00 & 30.00 & 1.03 & 84.11
\end{tabular}

Table 3. Levels of the Different Adsorption Parameters

\begin{tabular}{ccc} 
Factors & Low level $(-1)$ & High level $(+1)$ \\
\hline A: Ratio & 4.0 & 19.00 \\
\hline B: Concentration (mg/L) & 20.00 & 100.00 \\
\hline C: $\mathrm{pH}$ & 2.00 & 9.00 \\
\hline D: Time $(\min )$ & 30.00 & 150.00
\end{tabular}

Table 3. The Different Tests with the Actual Values

\section{Analysis of Variance (ANOVA)}

The ANOVA tests show the statistical significance of each of the effects by performing a comparison between the root mean square versus an experimental error estimate. Effects with probabilities that are less than the threshold value $\alpha=0.05$ are significantly different from zero at a $95.0 \%$ confidence interval. The coefficient of determination $\mathrm{R}^{2}$ indicates that the fitted model explains $98.2246 \%$ of the variability in capacity and $90.445 \%$ of the variability in yield (Table 5). In addition, it indicates that the regression is 
statistically significant. The mathematical models (equation 5 and 6) that relate the two responses to the different factors involved in adsorption are obtained through the statgraphics software after performing the ANOVA.

Capacity (mg/g) $=-0.0425343+0.00484747 *$ Ratio + $0.000927297 *$ Concentration $+0.0211225 * \mathrm{pH}-0.000184983 *$ Time + 0.000158499*Ratio*Concentration - 0,00173837*Ratio*pH + 7.89103E$7 *$ Ratio*Time $\quad+\quad 0.000837561 *$ Concentration*pH + $0.0000122958 *$ Concentration*Time $\quad-\quad 0.0000799853 * \mathrm{pH}^{*}$ Time (5)

Yield (\%) $=54.5181+1.31561 *$ Ratio - 0.681916*Concentration + $3.36134 * \mathrm{pH}-0.155272 *$ Time $+0.0185701 *$ Ratio*Concentration $0.315476 *$ Ratio*pH $\quad-\quad 0,00601011 *$ Ratio*Time + $0.0710228 *$ Concentration* $\mathrm{pH}+0.00246331 *$ Concentration*Time + $0.00493775 * \mathrm{pH}^{*}$ Time (6) 
Table 4. ANOVA Table of Adsorption Capacity and Removal Efficiency of Methylene Blue

\section{Analysis of Variance for Capacity}

\begin{tabular}{|c|c|c|c|c|c|}
\hline Source & Sum of Square & DDL & Quadratic mean & F Repor & Proba \\
\hline A:Ratio & 0.021 & 1 & 0.0213226 & 1.34 & 0.3309 \\
\hline B:Concentration & 1.834 & 1 & 1.83364 & 115.19 & 0.0017 \\
\hline C:pH & 0.382676 & 1 & 0.382676 & 24.00000 & 0.016200 \\
\hline D:Time & 0.000856 & 1 & 0.000856 & 0.050000 & 0.831500 \\
\hline $\mathrm{AB}$ & 0.036175 & 1 & 0.036175 & 2.270000 & 0.228800 \\
\hline AC & 0.033316 & 1 & 0.033316 & 2.090000 & 0.243800 \\
\hline $\mathrm{AD}$ & 0.000002 & 1 & 0.000002 & 0.000000 & 0.991700 \\
\hline $\mathrm{BD}$ & 0.013933 & 1 & 0.013933 & 0.880000 & 0.418500 \\
\hline CD & 0.004514 & 1 & 0.004514 & 0.280000 & 0.631300 \\
\hline Blocs & 0.315568 & 3 & 0.105189 & 6.610000 & 0.077600 \\
\hline Total error & 0.047754 & 3 & 0.015918 & & \\
\hline Total (corr.) & 2.68976 & 15 & & & \\
\hline \multicolumn{6}{|c|}{$\begin{array}{c}\text { R-square }=98.2246 \text { percent }(\mathrm{s}) \\
\text { Mean absolute error }=0.0448153\end{array}$} \\
\hline
\end{tabular}

\section{Analysis of Variance for Yield}

\begin{tabular}{|c|c|c|c|c|c|}
\hline Source & Sum of Square & DDL & Quadratic Mean & F Repor & Proba \\
\hline A:Ratio & 21.285 & 1 & 21.2855 & 0.070 & 0.802 \\
\hline B:Concentration & 530.570 & 1 & 530.570 & 1.860 & 0.266 \\
\hline C:pH & 3862.340 & 1 & 3862.340 & 13.540 & 0.0350 \\
\hline D:Time & 140.7460 & 1 & 140.7460 & 0.490 & 0.5330 \\
\hline $\mathrm{AB}$ & 496.5810 & 1 & 496.5810 & 1.740 & 0.2790 \\
\hline AC & 1097.270 & 1 & 1097.270 & 3.850 & 0.1450 \\
\hline $\mathrm{AD}$ & 117.0330 & 1 & 117.0330 & 0.410 & 0.5670 \\
\hline BC+bloc & 527.290 & 1 & 527.2900 & 1.850 & 0.2670 \\
\hline $\mathrm{BD}$ & 559.2160 & 1 & 559.2160 & 1.960 & 0.2560 \\
\hline $\mathrm{CD}$ & 17.203500 & 1 & 17.20350 & 0.060 & 0.8220 \\
\hline Blocs & 325.0240 & 2 & 162.5120 & 0.570 & 0.6170 \\
\hline Total error & 855.4550 & 3 & 285.1520 & & \\
\hline Total (corr.) & 8952.970 & 15 & & & \\
\hline
\end{tabular}




\section{Study of the Effect of Factors and their Interactions}

The Pareto chart (Figure 4) ranks the effects from the largest absolute value to the smallest absolute value. When the effect has a value greater than the threshold probability value, it is insignificant. The probabilities of the different effects are given in Table 5. For capacity, the effect of $\mathrm{pH}$ and dye concentration are the two effects that are significant. For yield, the effect of $\mathrm{pH}$ is the only significant effect. The interactions $\mathrm{AB}$ (interaction between ratio and concentration), $\mathrm{BD}$ (interaction between concentration and time), and $\mathrm{AD}$ (interaction between ratio and time) are not significant but they influence the capacity positively, while the interactions AC (interaction between ratio and $\mathrm{pH}$ ) and $\mathrm{CD}$ (interaction between $\mathrm{pH}$ and time) influence the capacity negatively. However, for the yield, the interactions AB, BD, and $\mathrm{CD}$ are not significant but they also contribute positively on the dye removal yield while the interactions AC and AD influence the yield negatively (Figure 6). The effect of the ratio of the different adsorbents and the effect of the time of the treatment process are not significant for both responses (Figure 5).

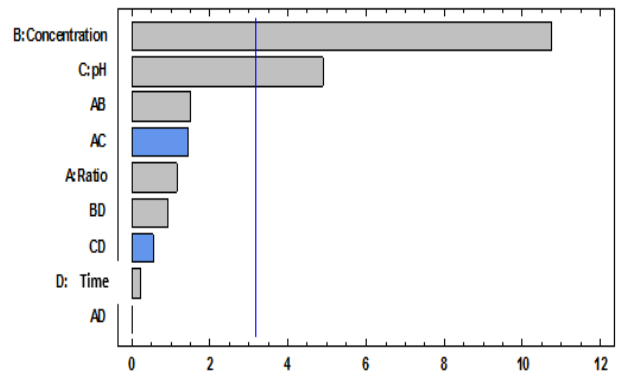

(a)

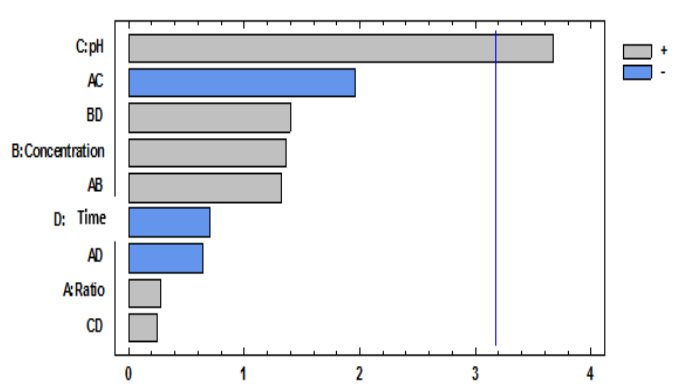

(b

Figure 4. Pareto Diagram of Capacity (a) and Yield (b)

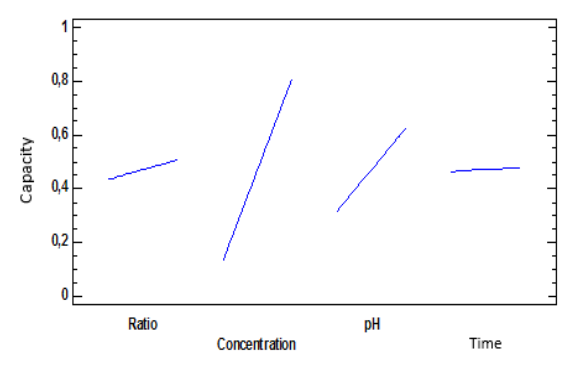

(c

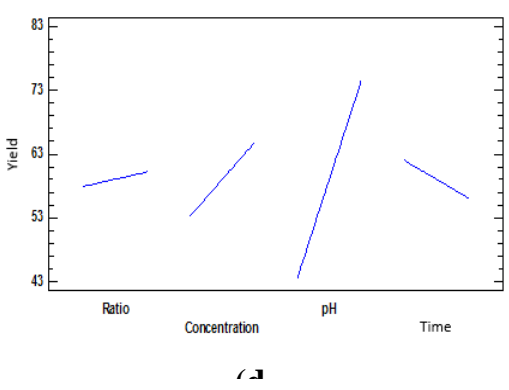

Figure 3. Graph of Direct Effects of Capacity (c) and Efficiency (d) 


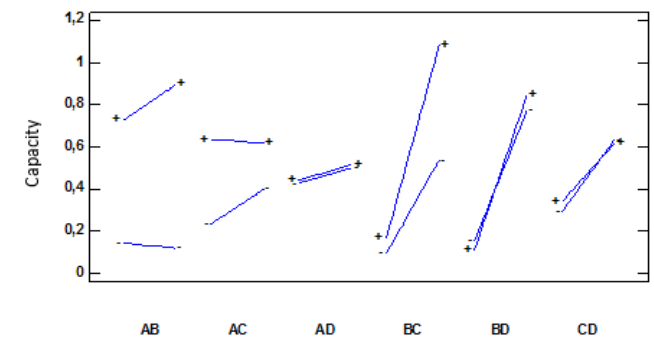

(e)

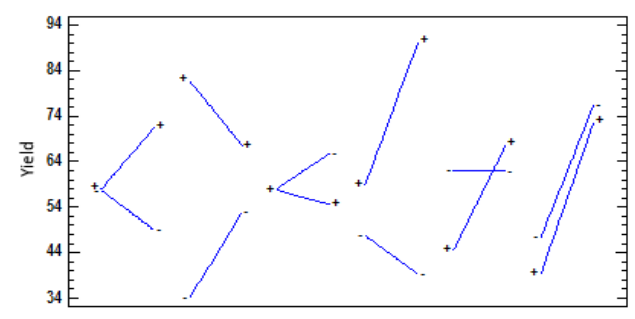

$A B \quad A C \quad A D \quad B C \quad B D \quad C D$

(f)

Figure 6. Diagram of Interactions between Capacity (e) and Yield (f)

\section{Desirability}

The desirability function simultaneously determines the optimal parameters of the input variables that can determine the optimal performance levels for one or more responses. It consists of converting each response (yi) into a desirability function (di) varying between $0 \leq \mathrm{di} \leq 1$. The value 0 is assigned when the factors lead to an unacceptable response. The value 1 is assigned when the response represents the maximum performance desired by the factors (Mourabet, El Rhilassi, El Boujaady, Bennani-Ziatni \& Taitai, 2017).

$$
D=\left(d_{1} * d_{2} * \ldots \ldots . . . d_{n}\right) \mathbf{1} / \mathbf{n}
$$

$\mathrm{n}$ : The number of responses in the measure

The desirability for each pair of factors is given in Table 6. Based on the observed responses, the best results were obtained for trial 2 and based on the responses predicted by the fitted model, the best results were obtained for trial 4. The maximum uptake capacity predicted by the model is $1.14105 \mathrm{mg} / \mathrm{g}$ under the following optimum conditions: at the ratio $=19$, concentration $=100$ $\mathrm{mg} / \mathrm{L}, \mathrm{pH}=9$, and time $=150 \mathrm{~min}$. The confirmation test showed an adsorption capacity of $1.1028 \mathrm{mg} / \mathrm{g}$ under the same conditions. The optimal yield predicted by the model is $98.55 \%$ under the following optimal conditions: ratio $=4$, concentration $=100 \mathrm{mg} / \mathrm{L}, \mathrm{pH}=9$, and time $=150 \mathrm{~min}$. The confirmation test showed a removal efficiency of $97.09 \%$ under the same conditions.

Table 5. Capacity and Performance Desirability

Observed

Planned

Observed

Planned

Observed

Planned

\begin{tabular}{ccccccc}
\hline Essay & Capacity & Capacity & Yield & Yield & Desirability & Desirability \\
\hline 1 & 0.109 & 0.102 & 43.750 & 46.426 & 0.189 & 0.198 \\
\hline 2 & 1.191 & 1.135 & 95.341 & 82.835 & 1.000 & 0.886 \\
\hline 3 & 0.071 & 0.161 & 28.409 & 34.324 & 0.068 & 0.150 \\
\hline
\end{tabular}




\begin{tabular}{lllllll}
\hline 4 & 1.125 & 1.098 & 90.000 & 93.915 & 0.935 & 0.952 \\
\hline 5 & 0.383 & 0.390 & 30.659 & 27.983 & 0.164 & 0.116 \\
\hline 6 & 0.131 & 0.187 & 52.500 & 65.006 & 0.244 & 0.336 \\
\hline 7 & 0.846 & 0.756 & 67.727 & 61.812 & 0.662 & 0.583 \\
\hline 8 & 0.196 & 0.223 & 78.636 & 74.722 & 0.396 & 0.400 \\
\hline 9 & 0.487 & 0.544 & 39.023 & 51.528 & 0.293 & 0.425 \\
\hline 10 & 0.189 & 0.196 & 75.795 & 73.119 & 0.380 & 0.375 \\
\hline 11 & 0.365 & 0.392 & 29.250 & 25.335 & 0.138 & 0.000 \\
\hline 12 & 0.094 & 0.005 & 37.954 & 32.039 & 0.150 & 0.071 \\
\hline 13 & 0.192 & 0.135 & 76.704 & 64.199 & 0.385 & 0.295 \\
\hline 14 & 1031 & 1.024 & 82.500 & 85.176 & 0.844 & 0.860 \\
\hline 15 & 0.082 & 0.055 & 32.727 & 36.642 & 0.109 & 0.122 \\
\hline 16 & 1.051 & 1.141 & 84.114 & 90.028 & 0.863 & 0.941
\end{tabular}

\section{Adsorption Kinetics}

The representation of the linear equations of the first-order adsorption, secondorder adsorption, intraparticle diffusion, and Elovich kinetic models is given in Figure 7. As shown in Table 7, the pseudo second order kinetics is the most adequate model to describe the phenomenon of adsorption of methylene blue on the composite material consisting of the mixture of titaniferous sand and attapulgite. The equilibrium adsorbed amount calculated from the pseudosecond order mathematical model is close to that obtained experimentally (Azoulay et al., 2020). The graphical representation of the intraparticle diffusion model does not pass through the origin. Therefore, this shows that the adsorption is controlled by a molecular diffusion film. These same results were found by Xiaoyu Chen, Song and Sun (2016).

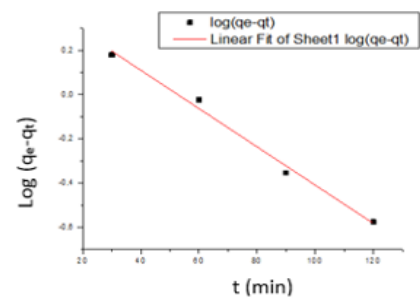

(a)

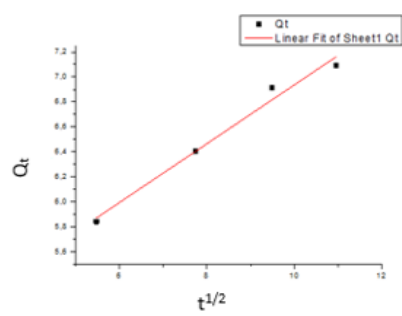

(c)

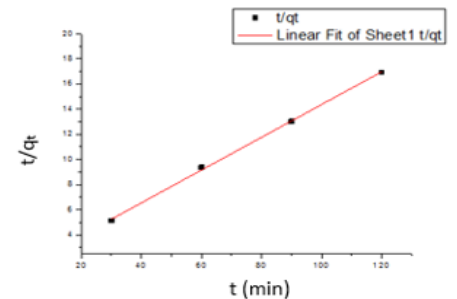

(b)

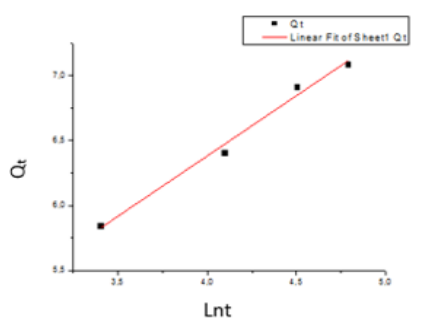

(d)

Figure 7. Kinetic Models: Pseudo-First Order (a), Pseudo-Second Order (b), Intraparticle Diffusion (c), Elovich Equation (d) 
Table 6. Kinetic Model Parameters for MB Adsorption on the Mixture of Adsorbents Thermodynamic Study

\section{Linear Equations}

Parameters

Titaniferous sand/Attapulgite

Linear equation of pseudo-first order kinetic

$$
\log \left(q_{e}-q_{t}\right)=-K_{1}+\log q_{e}
$$

(Xi Chen et al., 2020; Mekatel et al., 2015)

Linear equation of pseudo-second order

$$
\frac{\mathrm{t}}{\mathrm{q}_{\mathrm{t}}}=\frac{1}{\mathrm{~K}_{2} \mathrm{q}_{\mathrm{e}}^{2}}+\frac{1}{\mathrm{q}_{\mathrm{et}}}
$$
kinetic

\begin{tabular}{cc}
$\mathrm{R}^{2}$ & 0.987 \\
\hline $\mathrm{K}_{1}\left(\mathrm{mn}^{-1}\right)$ & 0.008 \\
\hline $\mathrm{q}_{\mathrm{e}}(\mathrm{cal})(\mathrm{mg} / \mathrm{g})$ & 1.577 \\
\hline $\mathrm{K}_{2}\left(\mathrm{~g} \cdot \mathrm{mg}^{-1} \cdot \mathrm{mn}^{-1}\right)$ & 0.012 \\
\hline $\mathrm{R}^{2}$ & 0.998 \\
\hline $\mathrm{q}_{\mathrm{e}}(\mathrm{cal})(\mathrm{mg} / \mathrm{g})$ & 7.686 \\
\hline $\mathrm{q}_{\mathrm{e}}(\exp )(\mathrm{mg} / \mathrm{g})$ & 7.356
\end{tabular}

(Bonetto et al., 2015; Salehi et al., 2020)

$$
\begin{aligned}
& \quad \begin{array}{l}
\text { Elovich equation } \\
\mathrm{Q}_{\mathrm{t}}=\frac{1}{\mathrm{~b}} \ln (\mathrm{ab})+\frac{1}{\mathrm{~b}} \ln \mathrm{t}
\end{array} \\
& \quad \text { (Xiaoyu Chen et al., 2016) } \\
& \quad \begin{array}{l}
\text { Intraparticle diffusion } \\
\mathrm{Q}_{\mathrm{t}}=\mathrm{K}_{\mathrm{d}} \mathrm{t}^{1 / 2}+\mathrm{C}
\end{array}
\end{aligned}
$$

\begin{tabular}{cc}
$\mathrm{R}^{2}$ & 0.985 \\
\hline $\mathrm{a}\left(\mathrm{mg} \cdot \mathrm{g}^{-1} \cdot \mathrm{mn}^{-1}\right)$ & 16.560 \\
\hline $\mathrm{b}\left(\mathrm{g} \cdot \mathrm{mg}^{-1}\right)$ & 1.078
\end{tabular}

(Xiaoyu Chen et al., 2016; Jayasantha Kumari

\begin{tabular}{cc}
$\mathrm{R}^{2}$ & 0.975 \\
\hline $\mathrm{K}_{\mathrm{d}}\left(\mathrm{mg} \cdot \mathrm{g}^{-1} \cdot \mathrm{mn}^{-0,5}\right)$ & 0.235 \\
\hline $\mathrm{C}$ & 4.580
\end{tabular}
et al., 2017).

The study of methylene blue removal efficiency as a function of temperature was carried out between 303K and 333K. This variation is given in Figure 8i. The adsorption of methylene blue decreases with increasing temperature. This indicates that the adsorption of methylene blue is favored at low temperatures. The variation of the free energy of the adsorption process is related to the equilibrium constant $\mathrm{K}_{\mathrm{d}}$ by the following relation:

$$
\begin{aligned}
\Delta G^{0} & =-R T I n K_{d} \quad \text { (Kavak, 2009; Saravanan et al., 2020) } \\
\ln K_{d} & =\frac{\Delta S^{0}}{R} \cdot \frac{\Delta H^{0}}{R T} \\
K_{d} & =\frac{q_{e}}{C_{e}}
\end{aligned}
$$

Where:

R: Constant of perfect gases,

$\mathrm{T}$ : Absolute temperature of the system in $(\mathrm{K})$,

$\mathrm{K}_{\mathrm{d}}$ : Adsorption equilibrium constant, qe: The equilibrium adsorbed amount (mg/g),

Ce: The equilibrium concentration $(\mathrm{mg} / \mathrm{L})$. 
The graphical representation of $\operatorname{lnK}_{\mathrm{d}}$ as a function of $1 / \mathrm{T}$ is a linear line whose slope is $-\Delta H^{0} / \mathrm{R}$ and the intercept $\Delta S^{0} / \mathrm{R}$ (Figure 8j). The different thermodynamic parameters are given in Table 8. The negative value of the enthalpy $\Delta \mathrm{H}^{0}$ shows that the adsorption reaction of methylene blue on the support is exothermic. In addition, the negative value of the entropy $\Delta \mathrm{S}^{0}$ corresponds to a decrease in the degree of disorder of the adsorbing particles. The positive values of the free energy $\Delta \mathrm{G}^{0}$ at $303 \mathrm{~K}, 313 \mathrm{~K}, 323 \mathrm{~K}$, and 333K indicate that the adsorption reaction is non-spontaneous.

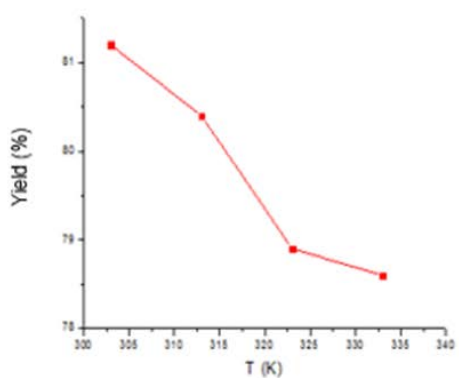

i

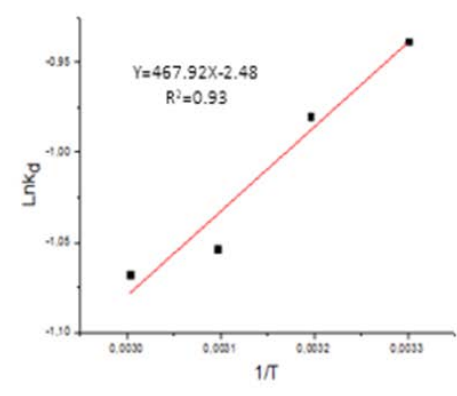

j

Figure 8. Variation of the Yield as a Function of the Temperature Evolution (i) and the Van't Hoff Curve (j)

Table 8.Thermodynamic Parameters of Methylene Blue Adsorption on the Composite Material

\begin{tabular}{|c|c|c|c|c|}
\hline Température (K) & $\mathbf{K}_{\mathbf{d}}$ & $\Delta G^{0}(\mathbf{k J} / \mathrm{mol})$ & $\Delta \mathbf{H}^{0}(\mathrm{~kJ} / \mathrm{mol})$ & $\begin{array}{c}\Delta \mathbf{S}^{\mathbf{0}}(\mathrm{kJ} / \mathrm{mol} \\
\mathrm{K})\end{array}$ \\
\hline 303 & 0.391 & 2363.720 & & \\
\hline 313 & 0.375 & 2550.170 & & \\
\hline 323 & 0.348 & 2829.680 & & \\
\hline 333 & 0.343 & 2956.370 & -3890.270 & -20.640 \\
\hline
\end{tabular}

\section{Conclusion}

In this study, a mixture of natural adsorbents was used for efficient removal of $\mathrm{MB}$. The efficiency of the composite material was significantly influenced by the $\mathrm{pH}$ of the solution and the initial concentration of MB. Full factorial design methodology involving the design of a screening design was used to investigate the influence of the four selected independent variables and to determine the optimal adsorption conditions. The study of the direct effects of the factors show that the percentage removal of the MB molecule increases by increasing the initial dye concentration and $\mathrm{pH}$. The optimized values, at which the maximum removal rate (98.55\%) was achieved, are obtained at ratio 
4, initial MB concentration (100 mg. $\mathrm{L}^{-1}$ ), $\mathrm{pH}=9$, and time $150 \mathrm{~min}$. The kinetic data suggest that the adsorption process of $\mathrm{MB}$ on the composite material is governed by the pseudo-second order adsorption mechanism $\left(\mathrm{R}^{2}=0.998\right)$. The thermodynamic study showed that the adsorption process was nonspontaneous and exothermic in nature. Therefore, this mixture of adsorbents can be used as stable, environmentally friendly, and effective adsorbents for wastewater treatment.

\section{References:}

1. Aarfane, A., Salhi, A., El Krati, M., Tahiri, S., Monkade, M., Lhadi, E. K. \& Bensitel, M. (2014). Kinetic and thermodynamic study of the adsorption of Red195 and Methylene blue dyes on fly ash and bottom ash in aqueous medium. Journal of Materials and Environmental Science, 5(6), 1927-1939.

2. Abbaz, M., Aba, R., El, R., Lhanafi, S. \& El, N. (2014). Elimination du bleu de méthylène dans l'eau par adsorption sur le sable titanifère (Removal of methylene blue from aqueous solution by adsorption onto the sand titaniferous). 5, 2418-2425.

3. Benguella, B. \& Yacouta-Nour, A. (2009). Elimination des colorants acides en solution aqueuse par la bentonite et le kaolin. Comptes Rendus Chimie, 12(6-7), 762-771.

4. Biophys, J. P. C., Aa, O. \& Aj, O. (2014). Journal of Physical Chemistry \& Kinetic Study of Decolorization of Methylene Blue with Sodium Sulphite in Aqueous Media: Influence of Transition Metal Ions. 4(2), 1-7.

5. Bonetto, L. R., Ferrarini, F., De Marco, C., Crespo, J. S., Guégan, R. \& Giovanela, M. (2015). Removal of methyl violet 2B dye from aqueous solution using a magnetic composite as an adsorbent. Journal of Water Process Engineering, 6, 11-20.

6. Bhattacharyya, K. G. \& Gupta, S. Sen. (2007). Adsorptive accumulation of $\mathrm{Cd}(\mathrm{II}), \mathrm{Co}(\mathrm{II}), \mathrm{Cu}(\mathrm{II})$.

7. $\mathrm{Pb}$ (II), and $\mathrm{Ni}(\mathrm{II})$ from water on montmorillonite: Influence of acid activation. Journal of Colloid and

8. Interface Science, 310(2), 411-424. https://doi.org/10.1016/j.jcis.2007.01.080

9. Chen, Xi, Li, P., Zeng, X., Kang, Y., Wang, J., Xie, H., Liu, Y. \& Zhang, Y. (2020). Efficient adsorption of methylene blue by xanthan gum derivative modified hydroxyapatite. International Journal of Biological Macromolecules, 151, 1040-1048.

10. Chen, Xiaoyu, Song, X. \& Sun, Y. (2016). with Core-Shell Structure for Dye Adsorption. 2016. 
11. El-Sayed, G. O. (2011). Removal of methylene blue and crystal violet from aqueous solutions by palm kernel fiber. Desalination, 272(1-3), 225-232.

12. Gupt, C. B., Bordoloi, S., Sekharan, S. \& Sarmah, A. K. (2020). Adsorption characteristics of Barmer bentonite for hazardous waste containment application. Journal of Hazardous Materials, 396(April), 122594.

13. Gürses, A., Doğar, Ç., Yalçin, M., Açikyildiz, M., Bayrak, R. \& Karaca, S. (2006). The adsorption kinetics of the cationic dye, methylene blue, onto clay. Journal of Hazardous Materials, 131(1-3), 217-228.

14. Jayasantha Kumari, H., Krishnamoorthy, P., Arumugam, T. K., Radhakrishnan, S. \& Vasudevan, D. (2017). An efficient removal of crystal violet dye from waste water by adsorption onto TLAC/Chitosan composite: A novel low cost adsorbent. International Journal of Biological Macromolecules, 96, 324-333.

15. Karim, A. B., Mounir, B., Hachkar, M., Bakasse, M. \& Yaacoubi, A. (2010). Removal of basic dye "methylene blue" in aqueous solution by Safi clay. Revue Des Sciences de l'Eau, 23(4), 375-388.

16. Kavak, D. (2009). Removal of boron from aqueous solutions by batch adsorption on calcined alunite using experimental design. Journal of Hazardous Materials, 163(1), 308-314.

17. Mekatel, E. H., Amokrane, S., Aid, A., Nibou, D. \& Trari, M. (2015). Adsorption of methyl orange on nanoparticles of a synthetic zeolite $\mathrm{NaA} / \mathrm{CuO}$. Comptes Rendus Chimie, 18(3), 336-344.

18. Oladipo, A. A., Gazi, M. \& Saber-Samandari, S. (2014). Adsorption of anthraquinone dye onto eco-friendly semi-IPN biocomposite hydrogel: Equilibrium isotherms, kinetic studies and optimization. Journal of the Taiwan Institute of Chemical Engineers, 45(2), 653664.

19. Ozer, C., Imamoglu, M. \& Turhan, Y. (2012). Toxicological \& Environmental Chemistry Removal of methylene blue from aqueous solutions using phosphoric acid activated carbon produced from hazelnut husks. November 2014, 37-41.

20. Salehi, E., Askari, M., Velashjerdi, M. \& Arab, B. (2020). Phosphoric acid-treated Spent Tea Residue Biochar for Wastewater Decoloring: Batch Adsorption Study and Process Intensification using Multivariate Data-based Optimization. Chemical Engineering and Processing Process Intensification, 158(July), 108170.

21. Salem, I. A. \& El-maazawi, M. S. (2000). Kinetics and mechanism of color removal of methylene blue with hydrogen peroxide catalyzed by some supported alumina surfaces. 41, 1173-1180. 
22. Saravanan, A., Sundararaman, T. R., Jeevanantham, S., Karishma, S., Kumar, P. S. \& Yaashikaa, P. R. (2020). Effective adsorption of Cu(II) ions on sustainable adsorbent derived from mixed biomass (Aspergillus campestris and agro waste): Optimization, isotherm and kinetics study. Groundwater for Sustainable Development, 11(July), 100460.

23. Taylor, P., Banat, F., Al-asheh, S., Zomaout, R. \& Qtaishat, B. (n.d.). Desalination and Water Treatment Photodegradation of methylene blue dye using bentonite as a catalyst. January 2015, 37-41.

24. Venkataraghavan, R., Thiruchelvi, R. \& Sharmila, D. (2020). Statistical optimization of textile dye effluent adsorption by Gracilaria edulis using Plackett-Burman design and response surface methodology. Heliyon, 6(10), e05219. 